\title{
The efficacy of ampicillin and Lactobacillus casei rhamnosus in the active management of preterm premature rupture of membranes remote from term
}

\author{
This article was published in the following Dove Press journal: \\ Drug Design, Development and Therapy \\ 30 August 2014 \\ Number of times this article has been viewed
}

\author{
Salih Burcin Kavak' \\ Ebru Kavak ${ }^{2}$ \\ Rasit Ilhan' \\ Remzi Atilgan' \\ Ozgur Arat' \\ Ugur Deveci ${ }^{3}$ \\ Ekrem Sapmaz' \\ 'Department of Obstetrics and \\ Gynecology, Firat Medical Center, \\ School of Medicine, Firat University, \\ ${ }^{2}$ Department of Obstetrics and \\ Gynecology, Special Medical Park \\ Hospital, ${ }^{3}$ Department of Pediatrics, \\ Firat Medical Center, School of \\ Medicine, Firat University, Elazig, \\ Turkey
}

Background: We aimed to investigate the treatment efficacy of ampicillin prophylaxis accompanied by Lactobacillus casei rhamnosus over the latency period following preterm premature rupture of membranes (PPROM).

Methods: Records of 40 patients who presented with PPROM between $23^{0 / 7}-31^{6 / 7}$ weeks were analyzed retrospectively. Patients were divided into two groups: group $1(n=20)$, treated with ampicillin; and group $2(\mathrm{n}=20)$, treated with ampicillin plus L. casei rhamnosus. Clinical and laboratory parameters were compared. Delta $(\Delta)$ values of each laboratory parameter were calculated by subtracting the value at delivery from the values at admission to the clinic.

Results: Gestational weeks at delivery ( $28.1 \pm 0.3$ weeks versus $31.5 \pm 0.4$ weeks), latency periods (12.3 \pm 1.5 days versus $41.4 \pm 4.4$ days), 5 -minute APGAR scores ( $6.8 \pm 0.1$ versus $7.8 \pm 0.1$ ), and birth weights $(1,320 \pm 98 \mathrm{~g}$ versus $1,947 \pm 128 \mathrm{~g})$ were significantly higher in group 2 . White blood cell (WBC) $\left(12,820 \pm 353 / \mathrm{mm}^{3}\right.$ versus $\left.11,107 \pm 298 / \mathrm{mm}^{3}\right)$, and neutrophil counts $\left(10.7 \pm 0.5 \times 10^{3} / \mathrm{L}\right.$ versus $\left.8.2 \pm 0.5 \times 10^{3} / \mathrm{L}\right)$ were significantly lower in group 2 at delivery. The $\Delta \mathrm{WBC}\left(2,295 \pm 74 / \mathrm{mm}^{3}\right.$ versus $\left.-798 \pm-406 / \mathrm{mm}^{3}\right), \Delta \mathrm{C}$-reactive protein $(5 \pm 0.04 \mathrm{mg} / \mathrm{L}$ versus $1.6 \pm 0.2 \mathrm{mg} / \mathrm{L})$, and $\Delta$ neutrophil $\left(3 \pm 0.2 \times 10^{3} / \mathrm{L}\right.$ versus $\left.0.2 \pm-0.1 \times 10^{3} / \mathrm{L}\right)$ were significantly lower in group 2 .

Conclusion: It seems that addition of $L$. casei rhamnosus to ampicillin prolongs the latency period in patients with PPROM remote from term.

Keywords: probiotic, antibiotic, latency period

\section{Introduction}

Spontaneous membrane rupture occurring before 37 weeks of gestation is referred to as preterm premature rupture of membranes (PPROM). In the literature, PPROM is divided into the three groups: previable PPROM ( $<23$ weeks), PPROM remote from term (from viability to $\sim 32$ weeks of gestation), and PPROM near term ( $\sim 32-36$ weeks of gestation). Management with antibiotics and antenatal steroids is recommended up to 34 weeks gestation, to prolong the pregnancy and reduce the risks associated with prematurity. ${ }^{1}$

In the management of PPROM, not only gestational age at delivery, but also, the duration of the latency period through which the fetus is exposed to a potentially unfavorable intrauterine environment should be taken into consideration. ${ }^{2}$ During the latency period, several events, such as the ascent of pathogenic microorganisms from the lower genital area, can create complications (eg, intrauterine infection, placenta abruptio, nonreassuring fetal heart rate tracings, or uterine contractions). ${ }^{3,4}$
Correspondence:

Salih Burcin Kavak

Firat University, School of Medicine,

Firat Medical Center, Department of

Obstetrics and Gynecology

23100 , Elazig, Turkey

Tel +90 4242333555 extn 2124

Fax +9042423791 38

Email burcinkavak@gmail.com 
Since the risk of ascendant infection increases in prolonged PPROM over 24 hours, the American College of Obstetricians and Gynecologists prepared clinical management guidelines and recommended use of prophylactic antibiotics in the management of PPROM. Corticosteroids are also recommended in PPROM, to reduce the risks of neonatal prematurity related complications. ${ }^{5}$

Lactobacillus spp., in the female urogenital tract, work as a barrier against infections. Besides, they compete with other microorganisms and control the vaginal flora. They inhibit the growth and proliferation of potential pathogens. This type of usage of probiotic lactobacilli for their protective and healing effects is interesting. ${ }^{6}$

The purpose of our study was to investigate the efficacy of giving probiotic Lactobacillus casei rhamnosus with ampicillin prophylaxis over the latency period, and maternal and neonatal morbidity, in cases of PPROM under 32 weeks of gestation.

\section{Methods}

This retrospective study was performed by the Firat University Department of Obstetrics and Gynecology, Elazig, Turkey, between July 2011 and June 2013. The study protocol was approved by the Firat University, Faculty of Medicine, Clinical Research Ethics Board. Clinical and laboratory parameters were determined from medical records.

Pregnant patients who were admitted for PPROM at $23^{0 / 7}-31^{6 / 7}$ weeks of pregnancy were classified into two groups according to treatment:

- Group 1 included 20 PPROM patients who received four doses of $1 \mathrm{gr} /$ day ampicillin $\left(\right.$ Ampisina ${ }^{\circledR}$ for injection $1 \mathrm{~g}$; Mustafa Nevzat, Istanbul, Turkey)

- Group 2 included 20 PPROM patients who received four doses of $1 \mathrm{gr} /$ day ampicillin plus a transvaginal application of 1 capsule $(341 \mathrm{mg}) /$ day, until labor of $L$. casei rhamnosus (Vagi-Flora ${ }^{\circledR}$ vaginal capsule; Laboratoires Lyocentre, Aurillac, France) ( $>40,000$ CFU)

Patients in active labor at the time of admission, those with fetomaternal infection, fetal distress, or vaginal bleeding, and those with other obstetric risk factors, such as pregnancy induced hypertension, gestational diabetes, intrauterine growth restriction (IUGR), fetal anomaly, and multiple pregnancies, were excluded from the study.

Diagnosis of PPROM was based on history and confirmed by observation of amniotic fluid collection on sterile speculum examination or with at least two positive ferning and nitrazine tests or, if required, with an AmniSure ${ }^{\circledR}$ ROM Test (AmniSure International LLC, Boston, MA, USA).
During examination, bimanual pelvic examination was avoided.

For confirmation of gestational age and evaluation of amniotic fluid volume, ultrasonography was performed. In the context of follow up for chorioamnionitis, daily clinical examination, daily ultrasonograph evaluation, and nonstress test were performed, and vital sign findings were collected at 6-hour intervals.

White blood cell (WBC) counts $\left(/ \mathrm{mm}^{3}\right)$, neutrophil count $\left(\times 10^{3} / \mathrm{L}\right)$, and C-reactive protein $(\mathrm{CRP})$ levels $(\mathrm{mg} / \mathrm{L})$ were checked once every 3 days, and the numbers at the time of admission and delivery were recorded and compared. Delta $(\Delta)$ values of each laboratory parameter were calculated by subtracting the value for each patient at delivery from the values at admission to the clinic.

Starting from $24^{0 / 7}$ weeks, betamethasone $6 \mathrm{mg}$ /day (in two doses per 24 hours) was given to all patients, for faster lung maturation.

Delivery indication criteria were as follows: nonpreventable, advanced delivery (eight or more uterine contractions in an hour and $/$ or $\geq 4 \mathrm{~cm}$ cervical dilatation); maternal infection; fetal distress; or attainment of $34^{0 / 7}$ gestational weeks. Maternal infection, especially chorioamnionitis, was diagnosed with two or more of the following criteria: maternal fever over $38^{\circ} \mathrm{C}$; maternal tachycardia over 120 beats/min; leukocytosis (over $20 \times 10^{3} / \mathrm{mm}^{3}$ ); uterine tenderness and irritability; foulsmelling vaginal leucorrhea; and fetal tachycardia over 160 beats/min. ${ }^{7}$

Vaginal delivery was preferred if an obstetric or maternal indication for Cesarean-section was not present. After delivery, 5-minute APGAR scores, birth weight (g), gestational age at delivery (weeks), and latency period (days) were recorded for each patient. All newborns were followed for adverse perinatal events.

In the statistical analysis of the data, the IBM SPSS for Windows Version 21.0 program (IBM Corp, Armonk, NY, USA) was used. The Mann-Whitney $U$ test was used to compare variables between groups. The Wilcoxon signedrank test and chi square ( $\chi^{2}$ test) were used for the comparison of variables in each group. $P<0.05$ was considered as significant.

\section{Results}

Records of a total 40 patients diagnosed with PPROM and without infection findings (clinically and by laboratory) at admission were assessed retrospectively. They were between $23^{0 / 7}-31^{6 / 7}$ gestational weeks. Mean maternal age (years), gravidity (number), parity (number), and gestational age 
Table I Obstetric characteristics of the patients

\begin{tabular}{lrrr}
\hline & $\begin{array}{c}\text { Group I } \\
(\mathbf{n}=\mathbf{2 0})\end{array}$ & $\begin{array}{c}\text { Group 2 } \\
(\mathbf{n}=\mathbf{2 0})\end{array}$ & P-value \\
\hline Maternal age (years) & $25.2 \pm 2.1$ & $24.7 \pm 2.3$ & NS \\
Gravidy (N) & $2.9 \pm 1.3$ & $2.7 \pm 1.1$ & NS \\
Parity (N) & $1.5 \pm 1.1$ & $1.7 \pm 1.2$ & NS \\
Gestational age to & $25.4 \pm 0.5$ & $25.3 \pm 0.5$ & NS \\
admission (weeks) & & & \\
\hline
\end{tabular}

Notes: Values are given as mean \pm SEM. NS $=P>0.05$ (Mann-Whitney $U$ test).

Abbreviations: SEM, standard error of the mean; NS, not significant.

at admission (week) are shown in Table 1. No statistically significant difference was observed between group 1 and group 2 in terms of these variables $(P>0.05$, Mann-Whitney $U$ test).

There were statistically significant differences between group 1 and group 2 in terms of gestational age at delivery, latency period, 5-minute APGAR score, and birth weight. These variables were higher in group 2 . The shortest latency period was 14 days and the longest was 70 days (mean $41.4 \pm 4.4$ days) in group 2 compared with 5 days and 28 days (mean 12.3 \pm 1.5 days), respectively, in group 1. Clinical parameters are shown in Table 2.

In our study CRP, leukocyte, and neutrophil counts were similar between groups 1 and 2 at the time of admission and delivery. But statistically significant differences were observed between groups for the WBC count at delivery, $\triangle \mathrm{WBC}$ levels, $\triangle \mathrm{CRP}$ levels, neutrophil count at delivery, and $\Delta$ neutrophil levels. The WBC counts, and CRP and neutrophil levels, at admission and delivery, and their $\Delta$ values are shown in Table 3.

$\Delta \mathrm{WBC}\left(2,295 \pm 74 / \mathrm{mm}^{3}\right.$ versus $\left.-798 \pm-406 / \mathrm{mm}^{3}\right), \Delta \mathrm{CRP}$ $(5 \pm 0.04 \mathrm{mg} / \mathrm{L}$ versus $1.6 \pm 0.2 \mathrm{mg} / \mathrm{L})$, and $\Delta$ neutrophil $\left(3 \pm 0.2 \times 10^{3} / \mathrm{L}\right.$ versus $\left.0.2 \pm-0.1 \times 10^{3} / \mathrm{L}\right)$ were significantly lower in group 2. Moreover, WBC $\left(12,820 \pm 353 / \mathrm{mm}^{3}\right.$ versus $\left.11,107 \pm 298 / \mathrm{mm}^{3}\right)$ and neutrophil counts $\left(10.7 \pm 0.5 \times 10^{3} / \mathrm{L}\right.$ versus $8.2 \pm 0.5 \times 10^{3} / \mathrm{L}$ ) were significantly lower in group 2 at delivery.

Table 2 Comparison of clinical parameters between group I and group 2

\begin{tabular}{lccl}
\hline & $\begin{array}{l}\text { Group I } \\
(\mathbf{n = 2 0})\end{array}$ & $\begin{array}{l}\text { Group 2 } \\
(\mathbf{n = 2 0})\end{array}$ & P-value \\
\hline $\begin{array}{l}\text { Gestational age at } \\
\text { delivery (weeks) }\end{array}$ & $28.1 \pm 0.3$ & $31.5 \pm 0.4$ & $\mathrm{~A}$ \\
Latency period (days) & $12.3 \pm 1.5$ & $41.4 \pm 4.4$ & $\mathrm{~A}$ \\
5-minute APGAR score & $6.8 \pm 0.1$ & $7.8 \pm 0.1$ & $\mathrm{~A}$ \\
Birth weight (g) & $1,320 \pm 98$ & $1,947 \pm 128$ & $\mathrm{~A}$ \\
\hline
\end{tabular}

Notes: Values are given as mean \pm SEM. $A=$ statistically significant $(P<0.05$, Mann-Whitney $U$ test).

Abbreviation: SEM, standard error of the mean.
Table 3 Comparison of laboratory parameters between group I and group 2

\begin{tabular}{lccl}
\hline & $\begin{array}{l}\text { Group I } \\
(\mathbf{n}=\mathbf{2 0})\end{array}$ & $\begin{array}{l}\text { Group 2 } \\
(\mathbf{n = 2 0 )}\end{array}$ & P-value \\
\hline WBC $\left(/ \mathrm{mm}^{3}\right)$ at admittance & $10,525 \pm 279$ & $11,904 \pm 704$ & $\mathrm{NS}$ \\
WBC $\left(/ \mathrm{mm}^{3}\right)$ delivery & $12,820 \pm 353^{\mathrm{a}}$ & $11,107 \pm 298$ & + \\
$\Delta \mathrm{WBC}$ & $2,295 \pm 74$ & $-798 \pm-406$ & + \\
$\mathrm{CRP}(\mathrm{mg} / \mathrm{L})$ at admittance & $3.6 \pm 0.06$ & $5.9 \pm 0.5^{\mathrm{a}}$ & $\mathrm{NS}$ \\
$\mathrm{CRP}(\mathrm{mg} / \mathrm{L})$ delivery & $8.6 \pm 0.5^{\mathrm{a}}$ & $7.5 \pm 0.7$ & $\mathrm{NS}$ \\
$\Delta \mathrm{CRP}$ & $5 \pm 0.04$ & $1.6 \pm 0.2$ & + \\
Neutrophil $\left(\times 10^{3} / \mathrm{L}\right)$ at & $7.7 \pm 0.3$ & $8 \pm 0.6$ & $\mathrm{NS}$ \\
admittance & & & \\
Neutrophil $\left(\times 10^{3} / \mathrm{L}\right)$ delivery & $10.7 \pm 0.5^{\mathrm{a}}$ & $8.2 \pm 0.5$ & + \\
$\Delta$ neutrophil & $3 \pm 0.2$ & $0.2 \pm-0.1$ & + \\
\hline
\end{tabular}

Notes: Values are given as mean \pm SEM. ${ }^{a} P<0.05$ (Wilcoxon rank test); NS $=P>0.05$ (Mann-Whitney $U$ test); $+=P<0.05$ (Mann-Whitney $U$ test).

Abbreviations: $\triangle$, delta; CRP, C-reactive protein; NS, not significant; SEM, standard error of the mean; WBC, white blood cells.

No findings of infection (maternal fever over $38^{\circ} \mathrm{C}$, maternal tachycardia [ $\geq 120$ beats/min], leukocytosis $\left[\geq 20,000 / \mathrm{mm}^{3}\right]$, uterine tenderness and irritability, foul-smelling vaginal leucorrhea, or fetal tachycardia [ $\geq 160$ beats/min]) were detected in group 2 up until the time of delivery. However three patients in group 1 showed signs and symptoms of clinical chorioamnionitis. While uterine tenderness and vaginal leucorrhea were the prominent symptoms in one patient, maternal fever and fetal tachycardia attracted attention in the other two. These three patients were delivered as soon as possible.

None of the newborns showed major fetal anomaly. In group 1, six newborns were intubated. One patient was extubated at 10 days and the other at 12 days. Two patients died due to sepsis, and two patients died due to respiratory distress syndrome.

In group 2, two newborns needed intubation and were extubated at 6 and 9 days. No laboratory and clinical infection findings were detected. No neurologic sequelae were identified among the surviving babies in both groups at 6 months.

\section{Discussion}

PPROM remote from term occurs in less than $1 \%$ of pregnancies, but it associated with significant maternal and fetal risks. ${ }^{8}$ It is a major cause of perinatal morbidity and mortality. In our study, we retrospectively compared the treatment efficacy of ampicillin and ampicillin plus $L$. casei rhamnosus over the latency period, and fetomaternal outcomes, in patients with PPROM remote from term.

More than one-half of women with midtrimester PPROM will deliver within 1 week and about three-quarters will 
deliver within 2 weeks. ${ }^{9}$ However, subsets of these women remain pregnant for an extended period of time, allowing the fetus to mature in utero. To prolong the latency period in PPROM, tocolytic treatment is used. But the value of tocolytic treatment after PPROM remains controversial. The primary argument against such treatment has been that PPROM is commonly associated with subclinical intrauterine infection. ${ }^{2}$ Nevertheless, tocolytic use is generally, but not uniformly, limited to 48 hours or less to attain steroid benefit.

Another therapy prolonging the latency period is the use of antibiotics. The latency period is significantly longer in PPROM cases managed actively with prophylactic antibiotics. ${ }^{7}$ For that purpose, one of the most preferred regimes is that recommended by the National Institute of Child Health and Human Development (NICHD). In this regime, intravenous (IV) ampicillin is started in the first 48 hours, and maintenance treatment with amoxicillin or enteric coated erythromycin is given in the following 5 days. ${ }^{5,10}$ In a previous study, in which imipenem/cilastatin, was given as a wide-spectrum antibiotic to PPROM patients, the latency period and perinatal morbidity was affected positively. ${ }^{11}$ The latency period was prolonged for 5 days when compared to the control group in that study. Although one study showed that prolongation of the latency period for more than 14 days had no positive effect on neonatal outcome, many medications were tried to prolong the latency period. ${ }^{10-13}$ However, none were as effective as our combination of ampicillin plus L. casei rhamnosus.

In our study, the latency period was $12.3 \pm 1.5$ days in group 1 and $41.4 \pm 4.4$ days in group 2. Antibiotic therapy was given to both groups. There was no maternal infectious morbidity, such as chorioamnionitis, endometritis, or wound infection, among patients taking L. Casei Rhamnosus in addition to prophylactic ampicillin.

Melamed et $\mathrm{al}^{2}$ identified a clear trend of decreased rate of adverse neonatal outcomes with increasing duration of the latency period, irrespective of gestational age at presentation with PPROM. Thus, it appears that for women with uncomplicated PPROM at gestational age 28-33 weeks, active management is beneficial, despite the potential negative effects associated with prolonged latency. ${ }^{2}$ Potential negative effects include lung injury (bronchopulmonary dysplasia), neurological injury (intraventricular hemorrhage and periventricular leukomalacia), necrotizing enterocolitis, and infectious morbidity. The indolent inflammatory environment and the presence of various proinflammatory mediators and cytokines in cases of subclinical chorioamnionitis may be associated with short and long term adverse neonatal outcome. ${ }^{14}$ Nonetheless, the reason for the higher rate of adverse neonatal outcomes in cases of uncomplicated PPROM is unclear. One possible explanation may be the presence of subclinical chorioamnionitis, which has been shown to complicate up to $25 \%-40 \%$ of cases of PPROM. ${ }^{15}$

Vaginal microflora are an important barrier against infections. Lactobacillus spp. work as a barrier against infections in the female urogenital system and provide a competitive protection against potential pathogens. Thus, clinical use of those probiotic agents, which are classified as "A" for use in pregnancy, is potentially interesting. ${ }^{16,17}$

L. casei rhamnosus is a pharmacologic agent that has been commercially used successfully for more than 20 years. L. casei rhamnosus produces a product named bacteriocin lactocin 160, which inhibits the growth of Gardnerella vaginalis in the vagina. ${ }^{18}$ Lactocin 160 is a quite specific antimicrobial product, is minimally irritative, and its intravaginal application is tolerable. ${ }^{19}$ It distributes in cell membrane and induces adenosine triphosphate flow. In this way, it kills the microorganisms associated with bacterial vaginosis; however, it does not affect the healthy vaginal microflora. ${ }^{20}$ Lactocin 160 use is safe and is an efficient treatment. ${ }^{21}$

The Food and Agriculture Organization/World Health Organization evaluated probiotics in the guideline published in 2002 and described L. casei rhamnosus as a healthy, beneficial probiotic, which can colonize in the vaginal ecosystem. ${ }^{22}$

\section{Conclusion}

We have found that the addition of $L$. casei rhamnosus to ampicillin lowered the laboratory parameters of infection and the rate of adverse neonatal and maternal events. The limitations of our study were the low number of the patients and retrospective nature of the study. So, multicenter prospective, randomized controlled studies are needed before recommending this as a mode of treatment.

\section{Disclosure}

The authors report no conflicts of interest in this work.

\section{References}

1. Mercer BM. Preterm premature rupture of the membranes. Obstet Gynecol. 2003;101(1):178-193.

2. Melamed N, Ben-Haroush A, Pardo J, et al. Expectant management of preterm premature rupture of membranes: is it all about gestational age? Am J Obstet Gynecol. 2011;204(1):48. e1-48. e8.

3. Gopalani S, Krohn M, Meyn L, Hitti J, Crombleholme WR. Contemporary management of preterm premature rupture of membranes: determinants of latency and neonatal outcome. Am J Perinatol. 2004;21(4):183-190.

4. Mercer BM. Preterm premature rupture of the membranes: current approaches to evaluation and management. Obstet Gynecol Clin North Am. 2005;32(3):411-428. 
5. ACOG Committee on Practice Bulletins-Obstetrics. ACOG Practice Bulletin No 80: premature rupture of membranes. Clinical management guidelines for obstetrician-gynecologists. Obstet Gynecol. 2007;109(4): 1007-1019.

6. Boris S, Suárez JE, Vázquez F, Barbés C. Adherence of human vaginal lactobacilli to vaginal epithelial cells and interaction with uropathogens. Infect Immun. 1998;66(5):1985-1989.

7. Queenan JT, Hobbins JC, Spong CY, editors. Preterm premature rupture of membranes. In: Mercer B. Protocols for High Risk Pregnancies. 5th ed. West Sussex: Wiley-Blackwell; 2010:448-460.

8. Yeast JD. Preterm premature rupture of the membranes before viability. Clin Perinatol. 2001;28(4):849-860.

9. Louis JM, Ehrenberg HM, Collin MF, Mercer BM. Perinatal intervention and neonatal outcomes near the limit of viability. Am J Obstet Gynecol. 2004;191(4):1398-1402.

10. Mercer BM, Miodovnik M, Thurnau GR, et al. Antibiotic therapy for reduction of infant morbidity after preterm premature rupture of the membranes. A randomized controlled trial. National Institute of Child Health and Human Development Maternal-Fetal Medicine Units Network. JAMA. 1997;278(12):989-995.

11. Ryo E, Ikeya M, Sugimoto M. Clinical study of the effectiveness of imipenem/cilastatin sodium as the antibiotics of first choice in the expectant management of patients with preterm premature rupture of membranes. J Infect Chemother. 2005;11(1):32-36.

12. Combs CA, Garite TJ, Maurel K, et al; Obstetrix Collaborative Research Network. 17-Hydroxyprogesterone caproate to prolong pregnancy after preterm rupture of the membranes: early termination of a double-blind, randomized clinical trial. BMC Res Notes. 2011;4:568.

13. Pasquier JC, Picaud JC, Rabilloud M, et al. Neonatal outcomes after elective delivery management of preterm premature rupture of the membranes before 34 weeks' gestation (DOMINOS study). Eur J Obstet Gynecol Reprod Biol. 2009;143(1):18-23.
14. Been JV, Rours IG, Kornelisse RF, et al. Histologic chorioamnionitis, fetal involvement, and antenatal steroids: effects on neonatal outcome in preterm infants. Am J Obstet Gynecol. 2009;201(6): 587.e1-587.e8.

15. Gibbs RS, Romero R, Hillier SL, Eschenbach DA, Sweet RL. A review of premature birth and subclinical infection. Am J Obstet Gynecol. 1992;166(5):1515-1528.

16. Atassi F, Brassart D, Grob P, Graf F, Servin AL. Lactobacillus strains isolated from the vaginal microbiota of healthy women inhibit Prevotella bivia and Gardnerella vaginalis in coculture and cell culture. FEMS Immunol Med Microbiol. 2006;48(3):424-432.

17. Saunders S, Bocking A, Challis J, Reid G. Effect of Lactobacillus challenge on Gardnerella vaginalis biofilms. Colloids Surf B Biointerfaces. 2007;55(2):138-142.

18. Aroutcheva AA, Simoes JA, Faro S. Antimicrobial protein produced by vaginal Lactobacillus acidophilus that inhibits Gardnerella vaginalis. Infect Dis Obstet Gynecol. 2001;9(1):33-39.

19. Dover SE, Aroutcheva AA, Faro S, Chikindas ML. Safety study of an antimicrobial peptide lactocin 160 , produced by the vaginal Lactobacillus rhamnosus. Infect Dis Obstet Gynecol. 2007;2007:78248.

20. Li J, Aroutcheva AA, Faro S, Chikindas ML. Mode of action of lactocin 160, a bacteriocin from vaginal Lactobacillus rhamnosus. Infect Dis Obstet Gynecol. 2005;13(3):135-140.

21. Anukam KC, Reid G. Probiotics: 100 years (1907-2007) after Elie Metchnikoff's observation. In: A Méndez-Vilas editor. Communicating Current Research and Educational Topics and Trends in Applied Microbiology. Badajoz: Formatex; 2007:466-474.

22. FAO/WHO Working Group on Drafting Guidelines for the Evaluation of Probiotics in Food. Guidelines for the Evaluation of Probiotics in Food. London, ON: Food and Agriculture Organization of the United Nations/World Health Organization; 2002. Available from: ftp://ftp.fao org/es/esn/food/wgreport2.pdf. Accessed July 15, 2014.

\section{Publish your work in this journal}

Drug Design, Development and Therapy is an international, peerreviewed open-access journal that spans the spectrum of drug design and development through to clinical applications. Clinical outcomes, patient safety, and programs for the development and effective, safe, and sustained use of medicines are a feature of the journal, which

\section{Dovepress}

has also been accepted for indexing on PubMed Central. The manuscript management system is completely online and includes a very quick and fair peer-review system, which is all easy to use. Visit http://www.dovepress.com/testimonials.php to read real quotes from published authors.

Submit your manuscript here: http://www.dovepress.com/drug-design-development-and-therapy-journal 